\title{
Does high-dose lovastatin therapy diminish the risk of iodinated contrast induced acute kidney injury? A double-blind placebo-controlled clinical trial
}

\author{
Mohammad Saad Forghani ${ }^{1}$, Khaled Fathizade ${ }^{1}$, Siamak Vahedi ${ }^{2}$, Sara Ataei ${ }^{3}$, Daem Roshani ${ }^{4}$ \\ ${ }^{1}$ Department of Internal Medicine, Kurdistan University of Medical Sciences, Sanandaj, Iran \\ ${ }^{2}$ Department of Cardiology and, Kurdistan University of Medical Sciences, Sanandaj, Iran \\ ${ }^{3}$ Department of Clinical Pharmacy, School of Pharmacy, Hamadan University of Medical Sciences, Hamadan, Iran \\ ${ }^{4}$ Department of Epidemiology and Biostatistics, Kurdistan University of Medical Sciences, Sanandaj, Iran
}

\section{A R T I C L E IN F O}

Article Type:

Original

\section{Article History:}

Received: 3 March 2017

Accepted: 13 October 2018

Published online: 10 January 2018

Keywords:

Iodinated contrast agent

Acute kidney injury

Lovastatin

\begin{abstract}
A B S T R A C T
Introduction: Contrast-induced acute kidney injury (CI-AKI) is one of the common causes of acute kidney injury. Various studies have been conducted to reduce the risk of CI-AKI. Objectives: In this study, we examined the effectiveness of lovastatin in preventing CI-AKI in patients who required iodinated contrast injection.

Patients and Methods: This double-blind clinical trial was conducted on 122 patients scheduled for coronary angiography, abdominal computed tomography (CT) scan, and pulmonary CT angiography. Patients were randomly divided into two groups of receiving lovastatin and placebo. Estimated glomerular filtration rate (eGFR) at baseline and 48 hours after iodinated contrast injection was calculated.

Results: The incidence of CI-AKI in all study population was 3.3\% (1.6\% in lovastatin group, and $5 \%$ in placebo group; $P=0.309$ ). A significant difference in the mean changes of eGFR (the differences in the mean of eGFR at the 48 hours after iodinated contrast injection versus baseline) between placebo and lovastatin group was observed $(P<0.001)$. This finding showed that, after intervention a further decline in the mean of eGFR in the placebo group than the lovastatin group was happened.

Conclusion: After iodinated contrast agent administration, in the lovastatin group mean change eGFR was significantly less than the placebo group. This finding indicated that highdose short-term lovastatin treatment may be effective on CI-AKI prevention.
\end{abstract}

Implication for health policy/practice/research/medical education:

Short-term high-dose administration of lovastatin can reduce the risk of contrast-induced acute kidney injury (CI-AKI).

Please cite this paper as: Forghani MS, Fathizade K, Vahedi S, Ataei S, Roshani D. Does high-dose lovastatin therapy diminish the risk of iodinated contrast induced acute kidney injury? A double-blind placebo-controlled clinical trial. J Renal Inj Prev. 2018;7(2):94-97. DOI: 10.15171/jrip.2018.22.

\section{Introduction}

After pre-renal azotemia and drug nephrotoxicity, contrast-induced acute kidney injury (CI-AKI) has shown as responsible for $11 \%$ of the leading reason of in-hospital acute kidney injury (AKI) and the third cause of inhospital AKI (1).

CI-AKI is described as a rise of serum creatinine more than $0.5 \mathrm{mg} / \mathrm{dL}$ or $25 \%$ increase from the baseline after 48 hours of administration of contrast (2).

CI-AKI is associated with more than $5 \%$ increase in hospital mortality rate in patients with chronic kidney disease (CKD) and $2.5 \%$ in patients without CKD. CI-AKI risk factors are divided into two groups of modifiable and non-modifiable. Non-modifiable risk factors include age, diabetes mellitus, advanced heart failure, CKD, cardiogenic shock and kidney transplant. In addition, modifiable risk factors include the volume of iodinated contrast agent, hypotension, anemia and dehydration, hypoalbuminemia (serum albumin $<3.5 \mathrm{~g} /$ $\mathrm{dL}$ ), administration of diuretics and angiotensin converting 
enzyme inhibitors, nonsteroidal anti-inflammatory drugs, intra-aortic pump balloon, and nephrotoxic antibiotics $(3,4)$.

Several approaches including hydration therapy (5), administration of sodium bicarbonate(6), $\mathrm{N}$-acetylcysteine (7), adenosine receptor antagonists (8), hemodialysis and hemofiltration in preventing CI-AKI have been assessed (9).

Since iodinated radio-contrast agents are involved in the pathophysiology of CI-AKI through inflammation, vasoconstriction and oxidative stress. Administration of statins, which are 3 hydroxy- 3 methylglutaryl coenzyme A (HMG-CoA) reductase inhibitors, has been considered to prevent CI-AKI. However, the result of several studies to assess the effect of statins on CI-AKI prevention has been controversial.

A meta-analysis by Singh et al showed which statins significantly decrease the risk of CI-AKI (10).

In contrast, another meta-analysis by Zhang et al did not show the protective effect of short-term high-dose statins to reduce CI-AKI (11).

Similarly the study by Abaci et al showed administration of rosuvastatin before coronary angiography did not reduce the risk of CI-AKI (12).

Another study to evaluate the effect of short-term highdose atorvastatin to reduce the risk of CI-AKI showed glomerular filtration rate (GFR) in patients receiving atorvastatin was higher than the placebo group after coronary angiography (13).

\section{Objectives}

This study aimed to evaluate the effect of lovastatin to prevent CI-AKI in patients receiving iodinated contrast agent.

\section{Patients and Methods \\ Study population}

This is a double-blind placebo-controlled clinical trial planned on a random group of patients who required elective coronary angiography and iodinated contrastenhanced computed tomography in Tohid hospital of Sanandaj, Iran in 2016. Patients who were required iodinated contrast injection in elective diagnostic procedures including computed tomography (CT) scan and coronary angiography were enrolled to the study. Exclusion criteria were acute kidney injury caused by conditions other than iodinated contrast administration, presence of acute coronary syndrome, acute myocardial infarction, sensitivity to statins and patient's dissatisfaction. Patients were randomly assigned into lovastatin and placebo groups using block randomization. Sixty-one patients who met the inclusion criteria were enrolled in each group (122 in total).

Administration of non-steroidal anti-inflammatory drugs, metformin, and diuretics stopped from 48 hours before to 48 hours after the procedure. Iso-osmolar iodinated contrast agent iodixanol was administered for all patients. Additionally, intravenous hydration with $1 \mathrm{~mL} / \mathrm{kg} / \mathrm{h}$ isotonic saline from 12 hours before the procedure and $1200 \mathrm{mg} \mathrm{N}$-acetyl cysteine twice daily from the day before through 24 hours after procedures were administered in all patients.

In the experimental group, $60 \mathrm{mg}$ of lovastatin (three $20 \mathrm{mg}$ tablets, Hakim pharmaceutical Company, Tehran, Iran) on the day before the procedure, the day of the procedure, and the day after the procedure were administered. The control group received placebo similar to lovastatin tablets (produced in the school of pharmacy, Hamadan University of Medical Sciences). Likewise, statins were continued in patients who were taking it before the study. Serum creatinine assessed at baseline (by the Jaffe method using standard kit manufactured by Pishtaz Teb Company, Tehran, Iran) and at 48 hours after iodinated contrast administration. Accordingly eGFR was calculated using the MDRD formula (14).

All patients' demographic information was recorded at the beginning of the study. In addition eGFR and serum creatinine were measured before and 48 hours after iodinated contrast injection. CI-AKI was defined as 0.5 $\mathrm{mg} / \mathrm{dL}$ increase in serum creatinine or $25 \%$ increase in the baseline level in the absence of other causes (2).

\section{Ethical issues}

The research followed the tenets of the Declaration of Helsinki; informed consent was obtained; the research was approved by the ethical committee of Kurdistan University of Medical Sciences (Grant \# 1394.143), and was registered at the Iranian registry of clinical trial database (identifier: IRCT2017041033359N1; http://en.search.irct.ir/).

\section{Statistical analysis}

Statistical analysis has been carried out by SPSS version 21. Results were analyzed using descriptive statistic formulas as percentage or mean. Given that the study is a clinical trial with inferential statistics, we used standard error of the mean to inference statistics information. Chisquare test, independent and dependent $t$ test and analysis of covariance (ANCOVA) were applied too. $P$ values $<0.05$ was considered statistically significant. The differences in the mean of eGFR at the baseline and 48 hours after the iodinated contrast injection in each group were expressed as mean changes.

\section{Results}

A total of 122 patients who were scheduled to coronary angiography and computed tomography were enrolled to the study. Around $48.4 \%$ of patients were male. They were randomly divided into two groups receiving lovastatin and placebo. The mean age of lovastatin and placebo groups were $56.9 \pm 13.9$ years and $54.5 \pm 15.5$ years respectively $(P$ $=0.37)$. The baseline mean serum creatinine in lovastatin and placebo groups were $1.01 \pm 0.02 \mathrm{mg} / \mathrm{dL}$ and 1.09 
$\pm 0.04 \mathrm{mg} / \mathrm{dL}$ respectively $(P=0.394)$. Accordingly, in lovastatin and placebo groups, the baseline eGFR was $72.7 \pm 1.8 \mathrm{~mL} / \mathrm{min} / 1.73 \mathrm{~m}^{2}$ and $69.9 \pm 2.6 \mathrm{~mL} / \mathrm{min} / 1.73$ $\mathrm{m}^{2}$ respectively $(P=0.121)$.

In this study, changes of eGFR in 48 hours after administration of iodinated contrast versus baseline in lovastatin group $\left(2.52 \pm 1.12 \mathrm{~mL} / \mathrm{min} / 1.73 \mathrm{~m}^{2} ; P=0.029\right)$ and placebo group $\left(4.24 \pm 1.38 \mathrm{~mL} / \mathrm{min} / 1.73 \mathrm{~m}^{2}, P=0.03\right)$ were significant (Table 1).

After the intervention, with regard to baseline eGFR, a significant difference in the mean changes of eGFR (the differences in the mean of eGFR at the 48 hours after iodinated contrast injection versus baseline) between placebo and lovastatin group was observed $(P<0.001)$. One patient $(1.6 \%)$ in the lovastatin group and three patients $(5 \%)$ in the placebo group suffered CI-AKI. The incidence of CI-AKI was calculated as 3.3\%. While CIAKI cases in the placebo group were higher than lovastatin group, however, it was not statistically significant ( $P=$ 0.309) (Table 2).

\section{Discussion}

Although, pathophysiology of CI-AKI is not exactly clear, nevertheless, different mechanisms have been proposed on the pathogenesis of CI-AKI. One of the considered mechanisms is vasoconstriction of afferent arterioles that reduces renal blood flow followed by medulla hypoxia and oxidative stress. In most cases, CI-AKI is temporary; however, it is often associated with increased risk of mortality. Therefore, prevention of CI-AKI, especially in at-risk patients, seems more critical. Statins had anti-

Table 1. Comparison of serum creatinine and glomerular filtration rate before and after iodinated contrast injection in the groups taking drug and placebo

\begin{tabular}{|c|c|c|}
\hline \multirow{2}{*}{ Variables } & \multicolumn{2}{|c|}{ Groups } \\
\hline & Lovastatin & Placebo \\
\hline \multicolumn{3}{|l|}{ MDRD eGFR $\left(\mathrm{mL} / \mathrm{min} / 1.73 \mathrm{~m}^{2}\right)$} \\
\hline Baseline eGFR & $72.71 \pm 1.88 \mathrm{SE}$ & $69.95 \pm 2.62 \mathrm{SE}$ \\
\hline After 48 hours eGFR & $70.18 \pm 1.6 \mathrm{SE}$ & $65.70 \pm 2.16 \mathrm{SE}$ \\
\hline eGFR changes & $2.52 \pm 1.12 \mathrm{SE}$ & $4.24 \pm 1.38 \mathrm{SE}$ \\
\hline$P$ value & 0.029 & 0.003 \\
\hline \multicolumn{3}{|l|}{ Serum creatinine $(\mathrm{mg} / \mathrm{dL})$} \\
\hline Baseline serum creatinine & $1.01 \pm 0.02 \mathrm{SE}$ & $1.09 \pm 0.04 \mathrm{SE}$ \\
\hline After 48 hours serum creatinine & $1.05 \pm 0.02 \mathrm{SE}$ & $1.12 \pm 0.03 \mathrm{SE}$ \\
\hline $\begin{array}{l}\text { Serum creatinine changes } \\
\text { (standard error of the mean ) }\end{array}$ & $-0.035 \pm 0.20 \mathrm{SE}$ & $-0.039 \pm 0.02 \mathrm{SE}$ \\
\hline$P$ value & 0.024 & 0.096 \\
\hline
\end{tabular}

Table 2. Incidence of $\mathrm{Cl}-\mathrm{AKI}$

\begin{tabular}{lc}
\hline Groups & Cl-AKI incidence, No. $(\%$ \\
\hline Lovastatin group, $\mathrm{n}=61$ & $1(1.6)$ \\
Placebo group, $\mathrm{n}=61$ & $3(5)$ \\
Total, $\mathrm{N}=122$ & $4(3.3)$ \\
$P$ value & 0.309 \\
\hline
\end{tabular}

inflammatory (15) and antioxidant effects and also improved endothelial function (16) that might have an advantageous effect in preventing CI-AKI.

After receiving iodinated contrast, patients in the lovastatin group experienced fewer changes of serum creatinine and GFR that was in contrast to placebo group. This means that after iodinated contrast injection fewer reduction of eGFR in the lovastatin group than the placebo group was existed. Consistent with prior studies, the results of our study indicated the beneficial effect of lovastatin to prevent CI-AKI.

However, Toso et al showed that in CKD patients who underwent coronary angiography or angioplasty, a shortterm high-dose atorvastatin had not significant effect on onset of CI-AKI ( $P=0.86)(17)$.

In a prospective, randomized trial conducted by Leoncini et al, patients with acute coronary syndrome subjected to coronary invasive strategy, received $40 \mathrm{mg} / \mathrm{d}$ of rosuvastatin, 15-44 hours before the procedure and 20 $\mathrm{mg} / \mathrm{d}$ after the procedure. They found that incidence of contrast-induced nephropathy was significantly lower compared to the control group $(P=0.003)(18)$.

\section{Conclusion}

Regarding fewer mean changes in eGFR in the lovastatin group than placebo group, and more occurrence of contrast induced acute kidney injury in the placebo group, the results of the present study highlights that shortterm high-dose administration of lovastatin may have protective effect on CI-AKI. However, further research on the effectiveness of lovastatin in reducing CI-AKI is required.

\section{Limitations of the study}

This study was conducted in a single center. Due to the limited sample size in this study, all patients receiving contrast in the coronary angiography, CT of chest, and pulmonary angiography procedures were enrolled.

\section{Acknowledgments}

We would like to show appreciation to our colleagues from department of internal medicine Kurdistan University of Medical Sciences.

\section{Authors' contribution}

MSF; considered initial idea to design the study, moreover, prepared and writing the final manuscript. SV and KF; contributed to gather data. MSF, SV and SA and DR contributed to data analysis and explanation of data.

\section{Conflicts of interest}

There were no points of conflicts.

\section{Ethical considerations}

Ethical issues (including plagiarism, data fabrication, double publication) have been completely observed by the authors. 


\section{Funding/Support}

The paper is extracted from internal medicine residency thesis of Khaled Fathizadeh. The study supported by a grant (\#143) from Kurdistan University of Medical Science.

\section{References}

1. Nash K, Hafeez A, Hou S. Hospital-acquired renal insufficiency. Am J Kidney Dis. 2002;39:930-6. doi: 10.1053/ ajkd.2002.32766.

2. Kidney Disease: Improving Global Outcomes (KDIGO) Acute Kidney Injury Work Group. KDIGO clinical practice guideline for acute kidney injury. Kidney Int Suppl. 2012; 2: 1-138. doi: 10.1038/kisup.2012.1.

3. Dangas G, Iakovou I, Nikolsky E, Aymong ED, Mintz GS, Kipshidze NN, et al. Contrast-induced nephropathy after percutaneous coronary interventions in relation to chronic kidney disease and hemodynamic variables. Am J Cardiol. 2005;95:13-9. doi: 10.1016/j.amjcard.2004.08.056.

4. Mehran R, Nikolsky E. Contrast-induced nephropathy: Definition, epidemiology, and patients at risk. Kidney Int Suppl. 2006;100:S11-5. doi: 10.1038/sj.ki.5000368.

5. Weisbord SD, Palevsky PM. Prevention of contrast-induced nephropathy with volume expansion. Clin J Am Soc Nephrol. 2008;3:273-80. doi: 10.2215/CJN.02580607.

6. Merten GJ, Burgess WP, Gray LV, Holleman JH, Roush TS, Kowalchuk GJ, et al. Prevention of contrastinduced nephropathy with sodium bicarbonate: a randomized controlled trial. JAMA. 2004;291:2328-34. doi: 10.1001/ jama.291.19.2328.

7. Marenzi G, Assanelli E, Marana I, Lauri G, Campodonico J, Grazi $\mathrm{M}$, et al. N-acetylcysteine and contrastinduced nephropathy in primary angioplasty. $\mathrm{N}$ Engl J Med. 2006;354:2773-82. doi: 10.1056/NEJMoa054209.

8. Kolonko A, Wiecek A, Kokot F. The nonselective adenosine antagonist theophylline does prevent renal dysfunction induced by radiographic contrast agents. J Nephrol. 1998;11:151-6.

9. Lee PT, Chou KJ, Liu CP, Mar GY, Chen CL, Hsu CY, et al. Renal protection for coronary angiography in advanced renal failure patients by prophylactic hemodialysis. A randomized controlled trial. J Am Coll Cardiol. 2007;50:1015-20. doi: 10.1016/j.jacc.2007.05.033.
10. Singh N, Lee JZ, Huang JJ, Low SW, Howe C, Pandit A, et al. Benefit of statin pretreatment in prevention of contrastinduced nephropathy in different adult patient population: systematic review and meta-analysis. Open Heart. 2014;1:e00127. doi:10.1136/openhrt-2014-000127.

11. Zhang T, Shen LH, Hu LH, He B. Statins for the prevention of contrast-induced nephropathy: A systematic review and meta-analysis. Am J Nephrol. 2011;33:344-51. doi. org/10.1159/000326269.

12. Abaci O, Arat Ozkan A, Kocas C, Cetinkal G, Sukru Karaca $\mathrm{O}$, Baydar $\mathrm{O}$, et al. Impact of Rosuvastatin on contrastinduced acute kidney injury in patients at high risk for nephropathy undergoing elective angiography. Am J Cardiol. 2015;115:867-71. doi:10.1016/j.amjcard.2015.01.007.

13. Bidram P, Roghani F, Sanei H, Hedayati Z, Golabchi A, Mousavi M, et al. Atorvastatin and prevention of contrast induced nephropathy following coronary angiography. J Res Med Sci. 2015;20:1-6.

14. Levey AS, Coresh J, Greene T, Marsh J, Stevens LA, Kusek JW, et al. Expressing the Modification of Diet in Renal Disease Study equation for estimating glomerular filtration rate with standardized serum creatinine values. Clin Chem. 2007;53:766-72. doi:10.1373/clinchem.2006.077180.

15. Sharyo S, Yokota-Ikeda N, Mori M, Kumagai K, Uchida K, Ito $\mathrm{K}$, et al. Pravastatin improves renal ischemia-reperfusion injury by inhibiting the mevalonate pathway. Kidney Int. 2008;74:577-84. doi:10.1038/ki.2008.210.

16. Wolfrum S, Jensen KS, Liao JK. Endothelium-dependent effects of statins. Arterioscler Thromb Vasc Biol. 2003;23:729-36.

17. Toso A, Maioli M, Leoncini M, Gallopin M, Tedeschi D, Micheletti C, et al. Usefulness of atorvastatin $(80 \mathrm{mg})$ in prevention of contrast-induced nephropathy in patients with chronic renal disease. Am J Cardiol. 2010;105:288-92. doi: 10.1016/j.amjcard.2009.09.026.

18. Leoncini M, Toso A, Maioli M, Tropeano F, Villani S, Bellandi F. Early high-dose rosuvastatin for contrastinduced nephropathy prevention in acute coronary syndrome: Results from the PRATO-ACS Study (Protective Effect of Rosuvastatin and Antiplatelet Therapy On contrast-induced acute kidney injury and myocardial damage in patients with Acute Coronary Syndrome). J Am Coll Cardiol. 2014;63:71-9. doi:10.1016/j.jacc.2013.04.105.

Copyright (c) 2018 The Author(s); Published by Nickan Research Institute. This is an open-access article distributed under the terms of the Creative Commons Attribution License (http://creativecommons.org/licenses/by/4.0), which permits unrestricted use, distribution, and reproduction in any medium, provided the original work is properly cited. 